\title{
FINGINDO ENTENDER: A RELAÇÃO ENTRE SUJEITO E MUNDO NAS OBRAS DE FERNANDO PESSOA E PAULO HENRIQUES BRITTO
}

Gabriel Dória Rachwal ${ }^{1}$

\begin{abstract}
RESUMO: O presente artigo tem como objetivo mostrar que as obras de Fernando Pessoa e Paulo Henriques Britto respondem, cada uma da sua forma, ao imperativo de significar o mundo. Fernando Pessoa lança mão do artifício do "poeta-dramaturgo", que é o artifício de forjar vozes que, de maneiras diferentes, "explicam" o mundo (como fazem Caeiro, Reis e Pessoa ele-mesmo). Britto também se questiona acerca dessa questão, mas a sua opção é criar uma voz poética que ironiza a relação de significação que o sujeito estabelece em relação ao mundo.
\end{abstract}

PALAVRAS-CHAVE: mundo, artifício, significação.

\begin{abstract}
ABSCTRACT: This paper has the objective of show that Fernando Pessoa and Paulo Henriques Britto give an answer to the imperative of mean the world. Fernando Pessoa use the trick of a play writter: He creates voices that, each one (Caeiro, Reis and Pessoa himself) at his own way, "explain" the world. Britto also try to answer the imperative, but his choice is to create a voice that ironizes the relation of meaning that happen between the subject and the world.
\end{abstract}

KEY-WORDS: world, trick, meaning.

Tanto Fernando Pessoa como Paulo Henriques Brito se debatem com um mundo que escapa a qualquer explicação. Como poetas, se questionam com a questão de a linguagem não ser capaz de abarcar o mundo, no entanto, cada um cria artifícios próprios para lidar com essa tensão. Veremos isso por meio da leitura de alguns poemas desses poetas. Para começar a comparação, seleciono o segundo poema da série "Uma doença", de Paulo Henriques Britto, retirado do livro Tarde (2007):

\footnotetext{
${ }^{1}$ Aluno do programa de mestrado da Universidade Federal do Paraná.
} 
O mundo está fora de esquadro. / Na tênue moldura da mente / as coisas não cabem direito. // A consciência oscila um pouco, / como uma cristaleira em falso. / Em torno de tudo há uma aura // que é claramente postiça. / O mundo precisa de um calço, / fina fatia de cortiça. (BRITTO, 2007, p. 26).

A primeira estrofe, em octossílabos que possuem os acentos sempre nas segunda, quinta e oitava sílabas, é apresentada a situação em que se encontra a relação do mundo com a "moldura da mente". As "coisas", os elementos que formam o mundo, não cabem direito nessa moldura, a mente não abarca esse mundo. Diante dessa situação, passando para segunda estrofe, a consciência oscila, comparada que é a uma cristaleira. Supostamente ela guarda objetos de valor, mas exerce sua função de forma precária já que oscila em falso. Cumpre mal seu papel de guardar as louças de valor, assim como a moldura da mente também não dá conta das coisas do mundo.

Note-se que o esquema acentual do poema oscila junto com a consciência (no quarto verso), quebrando o ritmo que, nesse verso e no seguinte (o quinto) não acompanha a acentuação da estrofe anterior e da posterior. Após os dois versos que tratam da consciência, voltando ao ritmo inicial, a descrição continua: "Em torno de tudo há uma aura / que é claramente postiça". Ora, postiça pode ser uma unha, cílios podem postiços, agora uma aura... estamos diante duma banalização irônica do elevado que é comumente operada por Britto. Uma "aura postiça", colocada posteriormente, artificialmente, está em torno de tudo, de todas as coisas. Que aura é essa? Quem a colocou em torno de tudo?

$\mathrm{Na}$ última estrofe do poema, uma afirmação sobre o mundo: ele precisa de um calço. Com um calço o mundo, talvez, não fique mais fora de esquadro, como descrevia o primeiro verso. A cristaleira que oscila em falso também encontraria uma solução para o problema com um calço. Ora, uma fina fatia de cortiça é algo postiço, algo posto depois (algo como a aura postiça?) e que estabiliza, enquadra, faz cessar a oscilação. Tanto o mundo como a consciência encontrariam estabilização se calçados por algo que não fazia parte deles. O mundo, então, se em estado natural (sem nada que lhe seja postiço), oscila em falso, fica fora de esquadro: só um calço o estabilizará. Será possível encontrar esse calço? Uma aura postiça pode resolver tal questão? Podemos confiar na cortiça? 
Configurado esse mundo, produtor de contingências, o que faz Britto? Dispondo da linguagem como instrumento (ainda que um instrumento um tanto arisco), enfrenta o mundo-enigma com muita auto-ironia, demolindo qualquer seriedade do assunto ${ }^{2}$, veja-se o poema "Sonetilho de Verão", do livro Trovar Claro":

\author{
SONETILHO DE VERÃO \\ Traído pelas palavras. \\ O mundo não tem conserto. \\ Meu coração se agonia. \\ Minha alma se escalavra. \\ Meu corpo não liga não. \\ A idéia resiste ao verso, \\ o verso recusa a rima, \\ a rima afronta a razão \\ e a razão desatina. \\ Desejo manda lembranças. \\ O poema não deu certo. \\ A vida não deu em nada. \\ Não há deus. Não há esperança. \\ Amanhã deve dar praia. (BRITTO, 1997, p. 81)
}

Enquanto o início de cada estrofe pinta um cenário angustiado e desiludido, o último verso delas solapa a seriedade. O poema, essa criação artificial, esse algo postiço ao mundo, não deu certo, não serviu de calço para esse mundo que não tem conserto. $O$ "Desejo manda lembranças" enquanto a razão, com seu impulso consciente e racional de abarcar o mundo, desatina. O mundo seguirá fora de esquadro, arquiteto que é de contingências irrefutáveis.

Fica exposto e ironizado o conflito do sujeito diante de um mundo sem conserto. Somente dispõe-se de uma ferramenta precária, se a intenção for abarcar esse mundo logicamente, esta ferramenta é a linguagem.

A respeito da relação da linguagem com o mundo, Alfredo Bosi diz em $O$ ser e $O$ tempo da poesia: "A distância que medeia entre a palavra e a coisa é, de fato, constitutiva

\footnotetext{
${ }^{2}$ Devo esta expressão "demolir a seridade do assunto" a uma resenha de Marcos Siscar sobre o livro Tarde.

${ }^{3}$ Este poema aparece traduzido para o inglês em Tarde (2007)
} 
do signo, está inscrita desde sempre na língua, que é filha da falta e do desejo, e não da plenitude e da unidade, amantes do êxtase e do silêncio.” (BOSI, 2000, p. 76).

Encontramos exposto, nessa citação, o descompasso entre linguagem (o instrumento da nossa consciência) e mundo, descompasso esse que vimos ilustrado no primeiro poema de Britto aqui tratado. Além disso, temos uma menção ao desejo que também aparece no "Sonetilho de verão" que acabamos de propor.

A linguagem é considerada filha do desejo e da falta $^{4}$. Ora, com uma filiação destas, não era mesmo de se esperar que ela fosse a ferramenta ideal para fazer o mundo deixar de oscilar. Lembremos, então, que a cortiça do primeiro poema aqui analisado não seria o material que melhor cumpriria a função de calço para alguma coisa, mas sim para fazer cessar ruídos.

Isolando ruídos pode até ser que se venha a acreditar que a cristaleira parou de oscilar, enquanto o que de fato aconteceu foi que somente o ruído cessou. Transpondo essa imagem para a relação da linguagem com o mundo, podemos dizer que a ferramenta "linguagem" pode até dar impressão de abarcar o mundo, no entanto a distância entre palavra e mundo, como nota Bosi, é inerente ao signo, logo, tudo que se pode chegar, inevitavelmente, é apenas uma ilusão.

No máximo os poemas de Britto acenam para o fim do ruído, mas nunca para uma solução dessa disputa entre o pensamento/a linguagem e o mundo. Vejamos, agora, como o heterônimo-mestre, Alberto Caeiro, lida com essas questões.

\section{O mestre, o mundo e a linguagem}

Em Caeiro, constataremos um posicionamento diferente no jogo de significação diante desse mundo-enigma, produtor de contingências, já conhecido nosso.

Caeiro é aquele que tem a resposta. Representa a figura do guru. Em vez de buscar um calço para o mundo, faz uma operação que, pelo menos no plano do seu próprio discurso, dispensa artifícios.

Comecemos nossa análise pelo fato de que também Caeiro nota que a linguagem é um problema, estando ela em descompasso com a Natureza, com o mundo:

\footnotetext{
${ }^{4} \mathrm{O}$ terceiro poema da série "Três peças circenses", do livro Trovar Claro, pode contribuir para esta leitura.
} 
"É que para falar dela [da Natureza] preciso usar da linguagem dos homens / Que dá personalidade às cousas, / E impõe nome às cousas, / Mas as cousas não tem nome nem personalidade: /Existem, (...)" (PESSOA, 2006, p. 218)

A linguagem causa um problema insolúvel para aquele que pretende um enquadramento do mundo na linguagem. Em Caeiro, diferentemente do que acontece em Britto, não se trata de um mundo arisco que rechaça "conclusões irrefutáveis", trata-se de uma linguagem que, por impor às coisas elementos postiços como "personalidade" e "nome", trai o mundo, estabelecendo, necessariamente, uma relação de desenquadramento com ele. E como Caeiro lida com essa linguagem falsa? Leia-se o poema XXXI:

\begin{abstract}
Se às vezes digo que as flores sorriem / E se eu disser que os rios cantam, / Não é porque eu julgue que há sorrisos nas flores / E cantos no correr dos rios... / É porque assim faço mais sentir aos homens falsos / A existência verdadeiramente real das flores e dos rios. // Porque escrevo para eles me lerem sacrifico-me às vezes / À sua estupidez de sentidos... Não concordo comigo, mas absolvo-me, / Porque só sou essa coisa séria, um intérprete da Natureza, / Porque há homens que não percebem a sua linguagem, / Por ela não ser linguagem nenhuma. (PESSOA, 2006, p. 220)
\end{abstract}

Caeiro reconhece uma função para o uso dessa linguagem falsa. É possível, através dela, mostrar a homens também falsos a "existência verdadeiramente real" de elementos da natureza.

O poeta reconhece isso como um sacrifício de si mesmo, pois, ao usar dessa linguagem, faz algo com que não concorda, contra-senso que está na base de sua poética. Todavia, ele não se importa com essa oscilação já que ela é natural. Caeiro é como o corpo do "Sonetilho de Verão" de Britto que, diante de um mundo sem conserto, não se preocupa: "Meu corpo não liga não".

No primeiro poema de $O$ guardador de rebanhos Caeiro pretende que aqueles que o lêem pensem-no como "qualquer cousa natural" e exemplifica com uma árvore. No poema XLVI, reforçando essa ambição, dizendo que sua busca consiste em: "Desembrulhar-me e ser eu, não Alberto Caeiro, / Mas um animal humano que a Natureza produziu." (PESSOA, 2006, p. 226). 
A ambição é estar integrado à Natureza, ao mundo. E Caeiro, diante de um mundo oscilante, aceita a oscilação e incorpora-se a ela. Os versos seguintes aos que acabo de citar mostram um pouco da aceitação dessa oscilação:

E assim escrevo, querendo sentir a Natureza, nem sequer como um homem, / Mas como quem sente a Natureza, e mais nada. / E assim escrevo, ora bem, ora mal, /Ora acertando com o que quero dizer, ora errando, / Caindo aqui, levantando acolá, / Mas indo sempre no meu caminho como um cego teimoso. (PESSOA, 2006, p. 226).

Ora uma coisa, ora outra. Caeiro, aqui, reconhece que se contradiz. Como fazia também no poema XXXI, entre outros. A contradição é aceita, sem restrições.

Sendo natural, não há problema algum, o objetivo é justamente a integração com um mundo que se apresenta novo, rebelde a significações, contraditório. É como se Caeiro incorporasse a rebeldia do mundo à sua poesia, à sua linguagem, que é rebelde em relação a pretensões de coerência, querendo, assim, incorporar a capacidade do mundo de sempre produzir contingências que impeçam uma conclusão irrefutável.

Eduardo Lourenço define a tarefa de Caeiro da seguinte maneira:

\begin{abstract}
Mas o que ele [Caeiro] é, do que vive em cada poema é da distância (infinita) que separa consciência e mundo, olhar e coisa vista. Caeiro nasce para a anular, mas é no espaço que separa olhar e realidade, consciência e sensação que o seu verbo (a sua voz) irônica e gravemente se articula. (LOURENÇO, 1981, p.36)
\end{abstract}

Entre nossos sentidos que captam o mundo, e o próprio mundo que está a nossa volta, está a linguagem. Entre nossa consciência e nossas sensações, também a linguagem. Entre a linguagem e cada um desses pólos, também uma falta, como é característico do signo (vide citação de Alfredo Bosi). Tal falta faz oscilar. O enquadramento (o fim da oscilação) nunca acontecerá?

Caeiro nasce para enquadrar, para anular a distância. E o que ele faz? Cria uma linguagem que oscila tanto quanto o mundo, contradizendo-se sem escrúpulos e impondo isso muitas vezes com uma irredutível dicção infantil e tautológica. 
Mundo e linguagem se irmanam em Caeiro quando este cria uma linguagem impositivamente oscilante, incorporando-se ao movimento natural do mundo, esse "arquiteto de contingências irrefutáveis" que encontramos em Britto.

Lendo um pouco mais os poemas do heterônimo de Pessoa, eu posso vir a pensar algo oposto a isso, mas não haveria espaço que bastasse. A significação tem que parar, pelo menos provisoriamente e não importando que seja de forma arbitrária.

\title{
Britto e Caeiro
}

Voltando ao poeta brasileiro, podemos dizer que Britto vive uma tensão entre (1) a busca de abarcar o mundo com a consciência e a linguagem e (2) um corpo (e um desejo, cf. "Sonetilho de Verão") que não compartilha dessa angústia que nunca se resolve. Cada poema seu é uma versão do mundo, refutável sempre, mas, por ora, enquanto não refutada, serve de verdade provisória (o modelo seria popperiano?). A dúvida sempre estará presente enquanto se estiver investigando o mundo e Britto convive com isso.

Gostaria de citar um outro poema em que se idealiza o potencial explicador do mundo que um construto humano pode ter. Trata-se do quarto poema da série "Balanços":

\author{
Antídoto contra a vida \\ E sua graça nefasta: \\ fugir de todo desejo, \\ buscar a alegria casta \\ das abstrações que ostentam \\ porte másculo e maiúsculo, \\ que explicam todo o universo \\ e cabem num magro opúsculo. (BRITTO, 2007, p. 17)
}

Desejo conota falta e dela o poema sugere que se fuja. Mas a fuga aí é justamente da vida desse mundo de contingências. A alegria que se busca é a alegria possível em meio às abstrações.

O mundo e seu viver, a contrariar o pensamento humano, podem ser controlados, ou ao menos, pode-se fingir esse controle quando o homem se refugia na linguagem, no pensamento e nas abstrações que esses processos permitem. 
As abstrações são muito mais previsíveis e, no caso de um poeta, um escritor, ele pode fazer essas abstrações explicativas caberem num "magro opúsculo", num poemeto que, tal como a cortiça (artifício) faz com a cristaleira que oscila em falso, nos dá a ilusão (ficção) do fim da trepidação do mundo. Uma dúvida, um hesitar, sempre será possível.

Enquanto Caeiro se integra através da linguagem a este mundo oscilante, Britto aposta na linguagem como um "tapa-buracos", um "tapa-faltas", um "satisfaz-desejos". O artifício é louvado, se o mundo não colabora, Britto fabrica a peça que falta. $\mathrm{O}$ "Poema de Natal" tem essa empreitada como tema:

Eis o prazer supremo, que não cansa / jamais: idolatrar o que criamos / à nossa vera imagem e semelhança. / Nada mais digno do mais puro amor / que essa anunciadíssima criança / em berço ou pálio ou página ou o que for,// desde de que seja nossa, e na medida / exata do desejo, nem maior / nem mais funda que a precisa ferida / que para preencher foi ela concebida. (BRITTO, 2007, p. 28)

O prazer supremo só poderia estar ligado a um desejo. A peça fabricada vem preencher a falta a que o desejo dá origem, vem preencher a ferida. A peça foi concebida para desempenhar esse papel. O poema está fazendo uma analogia do poeta e seu poema (sua criatura) com Deus e Jesus. Jesus é o messias (filho, criação de Deus, seu artifício); dele se espera salvação, mas Britto, como poeta materialista que é, rejeitando sempre o transcendental, mostra a possibilidade de o poeta ser o criador de sua salvação. Jesus é o artifício que Deus usa na tentativa de salvar os homens.

Britto utiliza a imagem sagrada para falar de uma criação mundana, que é a do poeta.

\section{Ricardo Reis e mais uma saída}

Em suas odes, Ricardo Reis, tendo Alberto Caeiro por mestre, expõe um modus vivendi que preza pelo "deixar passar", preza por tudo que for ameno. Diante da certeza de derrota, já que o tempo nos consumirá, é como se Reis buscasse o nada fazer para nada perder: "Não vale a pena / Fazer um gesto. / Não se resiste / Ao deus atroz / Que os próprios filhos / Devora sempre." (PESSOA, 2006, p. 253) 
Esse modo de vida é que rege a maneira como ele sugere a Lídia, sua "amada", que os dois vivam. Esse modo é um não-viver para que o vivido não venha a gerar sofrimento quando chegar a hora da renúncia obrigatória, imposta pela finitude da vida.

No poema "Vem sentar-se comigo" o contato entre os dois é mínimo, o tempo verbal dominante é o subjuntivo, que expressa hipóteses, especula sobre um futuro que, no caso do poema, não vem a se realizar. É uma maneira antisséptica de lidar com a vida. Com essa assepsia, Reis quer evitar o sofrimento: “Ao menos, se for sombra antes, lembrar-te-ás de mim depois / Sem que a minha lembrança te arda ou te fira ou te mova, / Porque nunca enlaçamos as mãos, nem nos beijamos / Nem fomos mais do que crianças". (PESSOA, 2006, p. 256-257)

Fica claro aí o ideal de não fazer nada para não sofrer quando vier o fim, que é para onde tudo caminha. $\mathrm{Na}$ sua "fuga" desse mundo e sua condição de finitude, um papel importante é dado, por Reis, para o estético.

A crítica Maria Helena Nery Garcez faz uma análise bastante produtiva nesse sentido. Ela analisa o heterônimo Ricardo Reis, principalmente, através da chave que aproxima "vida" e "jogo". A ode que é a grande base para sua tese é a "Ouvi contar que outrora, quando a Pérsia" (PESSOA, 2006, p. 267). Nesta ode temos dois sujeitos jogando xadrez "quando a invasão ardia na cidade". A cidade está sendo invadida, casas estão sendo saqueadas, crianças são trespassadas por lanças e mulheres violadas, mas os dois jogadores estão à parte de tudo isso. Eles estão entregues a um jogo em que sangue nenhum pode ser derramado, são as peças que "lutam". Reis tira daí uma lição: "Imitemos os persas desta história, / E, enquanto lá fora, / Ou perto ou longe, a guerra e a pátria e a vida / Chamam por nós, deixemos / Que em vão nos chamem, cada um de nós” (PESSOA, 2006, p.269). Como nota Maria Helena Nery Garcez:

É expressiva a preferência - ode triunfal às avessas - pela celebração de um jogo em que o jogador não necessita empenhar seu corpo, pois é jogo mental, em que ele também pode manter-se na cobiçada posição de espectador, à beira-tabuleiro. Não é um jogo coerente com a receita do decorrer a vida de Reis? (GARCEZ, 1990)

Na leitura de Garcez, isso tudo mostraria que Reis quer distância do mundo desconcertado que é o mundo real no qual as guerras implicam sangue e morte. Se podemos 
escolher entre esse mundo desconcertado e o mundo concertado do jogo, em que ninguém é trespassado por lança alguma, Reis não vê dúvida: “imitemos os persas desta história”. Quanto a isso Garcez afirma:

\begin{abstract}
A guerra real está sujeita a uma imprevisibilidade selvagem, caótica, incontrolável. Nela há desordem, dor e morte. É por isso talvez que ao confrontar e opor a guerra "a sério" e a guerra lúdica, é esta que é a preferida, porque esta é a outra depurada de suas imperfeições. $O$ ludo constitui uma reminiscência e uma prefiguração do paradisíaco. (GARCEZ, 1990, p. 36)
\end{abstract}

A vida "a sério" está associada a desconcerto. Reis busca refúgio dela no ludo, que Garcez associa muito acertadamente (se pensamos em Reis) com o paraíso. No ludo as imperfeições mundanas entram em concerto. Reis não hesita em abdicar da vida em nome do plano do jogo (que é também o plano estético).

O ludo pode ser comparado à abstração que víamos no quarto poema do ciclo Balanços de Paulo Henriques Britto e que também era uma promessa de fuga do desconcerto do mundo.

Naquele poema de Britto a busca da abstração era o "antídoto contra a vida". Ora, é justamente esse antídoto que busca Reis. Na vida não se encontra ordem, a vida é o lugar das imperfeições, o lugar onde se morre e se derrama sangue. Conforme nota Garcez, ao querer que imitemos os persas, Reis está “pretendendo estender a atitude lúdica para vida toda" (GARCEZ, 1990, p. 37).

Podemos dizer que para Reis o jogo é a possibilidade de Paraíso na Terra, assim como, em Britto, reside na linguagem a possibilidade de Paraíso. Em ambos os casos “paraísos artificiais”. Quanto a Reis, Garcez propõe: “a ordem espiritual do ludo concerta a material” (GARCEZ, 1990, p. 39), já quanto a Britto poderíamos dizer que a ordem material da linguagem concerta a ordem material do mundo.

O doente do conto "Uma doença" busca incessantemente, através de uma linguagem, abarcar, explicar o mundo (o quarto) que o cerca, acabando, por fim, escrevendo um relato do processo todo. É a busca do entendimento através do registro, a 
busca da criação de um "magro opúsculo" que tudo explique, dê ordem, forje um mundo em concerto ${ }^{5}$.

O crítico Júlio França, em artigo a respeito de Paulo Henriques Britto, faz a seguinte observação quanto ao papel do poeta: "Se o mundo está fora dos eixos, o poeta habitaria um espaço de resistência onde sua fala está, por um átimo, livre das pressões contingentes" (FRANÇA, 2003, p. 156). Notemos que França está dizendo isso em 2003 tendo por base os livros Mínima Lírica e Trovar Claro. Ele já flagrara exatamente a dinâmica que, neste trabalho, flagramos em poemas que em sua maioria constam do livro Tarde que é de 2007.

\section{Reis, Caeiro e Britto: resposta ao mundo-enigma}

Comparando agora Britto, Caeiro e Reis podemos constatar que os três poetas procuram, cada qual de um jeito próprio, relacionar-se com o mundo e seu caráter de ser sempre contingente. Podemos dizer que todos os três apostam nos paraísos artificiais que a linguagem permite criar.

Para Britto a solução reside justamente no ato criativo que está relacionado à satisfação, ao próprio prazer e a possibilidade de mudança do vivido através da experiência da escrita. A linguagem permite que o sujeito lance desafios ao mundo, assim como este desafia o sujeito incessantemente. O primeiro poema do ciclo Balanços faz justamente isso, apresenta postulados como "A morte tem que esperar", enquanto sabemos que a regra da morte é ser, em grande medida, imprevisível.

Caeiro também está num embate, mas seu embate é para conseguir acompanhar a ordem natural, selvagem e desconcertada do mundo. Seus artifícios poéticos vêm no sentido de imitar, integrar-se ao movimento desordenado e nesse sentido, seus deliberados paradoxos ganham lógica.

E quanto a Reis, como acabamos de ver, tem-se uma tentativa de fazer um "lance" que drible a vida e sua contingência. Emprega-se a vida num jogo, espaço que, se comparado à vida, é muito mais controlável.

Não será sempre o caso de criar uma ilusão?

\footnotetext{
${ }^{5} \mathrm{O}$ termo "concerto" aqui se encaixa muito bem, já que o opúsculo de um poema conta muito com a sonoridade, a musicalidade da linguagem.
} 
Sinto-me diante de "sistemas" poéticos que se esforçam por bem localizar questões com que a vida nos interpela e dá respostas (poemas) em troca. Tentativas de significar e, portanto, situar o sujeito no mundo. Todas essas tentativas, sempre deixando alguma "pulga atrás da orelha", alguma falha na construção.

Nesse sentido, Britto é o mais explícito. A dúvida parece acompanhar sua trajetória sempre, assim como uma certa "falta de seriedade". Britto faz questão de mostrar sempre o caráter insolúvel do "estar-no-mundo" e ironiza a condição de buscar sempre apaziguar isso com interpretações várias. Não que ele renuncie a interpretações, mas torna explícito o teor de ilusão que elas sempre contêm.

Não creio que esta ironia esteja presente, com tal intensidade, em Caeiro e em Reis. Por mais que possamos rir, muitas vezes, quando nos deparamos com o modus vivendi que cada um deles sugere, os dois heterônimos de Pessoa querem crer na resposta que encontraram para apaziguar o "estar-no-mundo". Não quero sugerir que eles estão errados ao impor uma resposta, nós precisamos fazer isso diariamente, precisamos assumir verdades. "Tudo parece o que é" quando precisamos decidir ou renunciar.

O fato é que, enquanto em cena (enquanto fala a voz no poema), Reis e Caeiro não deixam evidente uma ironia quanto à resposta que dão ao mundo-enigma: é por isso que Caeiro pode, por exemplo, ocupar a figura de mestre. Já Britto, em cena, ironiza a si próprio, desconstrói seu artifício.

\section{O poeta dramaturgo e o fingimento de Britto}

A orquestração dessas muitas vozes no Drama em gente tem como um dos pontos centrais o drama da significação, a crise do sujeito ao se defrontar com o mundo-enigma e ser incumbido de dar-lhe sentido e escolher como agir. O Fernando Pessoa orquestrador dos heterônimos escolheu expor o drama da significação através da criação das várias vozes, mostrando como cada uma delas se debate com a questão.

Do convívio das respostas provisórias, com a necessidade de se impor um ponto final, nasce uma angústia: é preciso continuar a caminhar sem garantia de que há um caminho confiável pela frente e não um abismo. Na terceira estrofe do terceiro poema do ciclo "Sete peças acadêmicas", encontramos: No truth can be pried away / By Archimede's 
lever - / For wich no fulcrum can be found. / Not anywhere. Not ever. (BRITTO, 2007, p. 69)

Não há uma verdade que possa ser sustentada. Todas as versões terão suas falhas. Ver ou ter uma versão do mundo por escrito (na linguagem) pode, muito bem, ser o mesmo que se enganar. Mas, lemos em Pessoa ele-mesmo: "Se ver é enganar-me, / Pensar um descaminho, / Não sei. Deus os quis dar-me /Por verdade e caminho." (PESSOA, 2006, p. 160)

Temos aqui uma invocação de "Deus" de um modo que, entre os poetas aqui envolvidos, só mesmo em Pessoa ele-mesmo poderia aparecer. Esse Deus permite ao sujeito da voz um determinado entendimento do mundo que, se não for o entendimento certo, ao menos vale como certo, já que é do que dispõe o sujeito. Da mesma forma, mas sem expor Deus, vimos Britto trabalhando em cima do postulado "Tudo parece o que é".

Em Pessoa ele-mesmo uma abdicação do questionar-se sobre estar-se ou não a pensar e ver corretamente. Em Britto o reconhecimento do imperativo de afirmar a correção do que se vê e pensa, apesar de todas as contingências que o mundo venha interpor a isso. O fingimento está na base dessas posições.

\section{REFERÊNCIAS BIBLIOGRÁFICAS:}

BOSI, Alfredo. O ser e o tempo da poesia. Companhia das Letras: São Paulo, 2000.

BRITTO, Paulo Henriques. Trovar Claro. São Paulo. Companhia das Letras, 1997. . Tarde. São Paulo. Companhia das Letras, 2007.

FRANÇA, Júlio. Anacrônico, pois poeta: linguagem, memória e resistência na poesia de Paulo Henriques Britto. In: Revista do Centro de Estudos Portugueses, v23, n. 23, pp. 147-167. Faculdade de Letras da UFMG, Belo Horizonte, 2003.

GARCEZ, Maria Helena Nery. O tabuleiro antigo. Edusp: São Paulo, 1990.

LOURENÇO, Eduardo. Fernando Pessoa Revisitado. Moraes Editores: Lisboa, 1981. (p. $33-45)$

PESSOA, Fernando. Obra poética. Rio de Janeiro. Nova Aguilar. $3^{a}$ edição, 2006. . Obras em prosa. Rio de Janeiro. Nova Aguilar.1 ${ }^{a}$ edição, 2004. 